\title{
Virtualization and cloud computing: The pathway to business performance enhancement, sustainability and productivity
}

\author{
Emmanuel Chinomso Ogu*, Omotunde Ayokunle, Mensah Yaw, Ogbonna Achimba \\ Department of Computer Science and Information Systems, School of Computing and Engineering Sciences, Babcock University, Ilishan- \\ Remo, Ogun State
}

Email address:

ecoxd1@yahoo.com (Emmanuel C. O.), ayo_omotunde@yahoo.com (Omotunde A. A.), mensahyaw1983@yahoo.com (Mensah Y.), acogbonna06@yahoo.com (Ogbonna A. C.)

\section{To cite this article:}

Emmanuel Chinomso Ogu, Omotunde Ayokunle, Mensah Yaw, Ogbonna Achimba. Virtualization and Cloud Computing: The Pathway to Business Performance Enhancement, Sustainability and Productivity. International Journal of Business and Economics Research.

Vol. 3, No. 5, 2014, pp. 170-177. doi: 10.11648/j.ijber.20140305.12

\begin{abstract}
Cloud computing, and the technology of virtualization which drives its foundations, lead the pack of Information Technology (IT) solutions for business that have emerged and kept transforming businesses in recent years. While in acknowledgement of the fact that numerous researches have emerged in recent times on the concepts of virtualization and cloud computing, trying to address issues relating to management, complexity, operability, service delivery, security, amongst others, very little to no effort has been made to study how these technologies impact the dynamic business environment of the $21^{\text {st }}$ century and the benefits they could hold for businesses of the digital age. In light of this, this paper gives a theoretical review of the business environment as it was before and shortly after the advent of IT, in such a way that novices as well as experts in business and IT would be able to identify with and understand the interactions that have always existed amongst these industries. It further goes on to provide a detailed exposé on cloud computing and virtualization as it affects the business environment of the $21^{\text {st }}$ century, right from its inception and origins, to survey its history, basic concepts, current trends, modes of deployment and use, as well as the benefits they provide for businesses in our world. It brings in some proven industry perspectives and opinions and presents new insights into what the future has to offer with these twin technologies for both the worlds of business and IT.
\end{abstract}

Keywords: Virtual Machine Monitor / Hypervisor, Virtualization, Cloud Computing, IT

\section{Introduction}

That our world is on the edge of an ICT revolution is by now well understood. Computers and ICT has revolutionized every aspect of human endeavour in our $21^{\text {st }}$ Century world in a very remarkable way, and business has not been in any way left out - accounting directly for laudable increase in profit and returns on investment in recent years. With more advancements waiting in line in Computing and ICT, it would be no gainsaying the fact that these may soon hold the key to business performance enhancement, sustainability and productivity in the coming years. It is therefore imperative that the dynamic business environment of our era strategizes and repositions in order to partake of the limitless benefits and opportunities that Computing and ICT currently offers; and also align congruently, so as not to miss out on soon coming benefits they would offer to our dynamic business environments.

The Business Environment is defined as "the combination of internal and external factors that influence a company's operating situation. The business environment can include factors such as: clients and suppliers; its competition and owners; improvements in technology; laws and government activities; and market, social and economic trends" [1]. From this definition, it is made easily very obvious that the key to progress and excellence in business may rely to a large extent on a proper understanding of these business environmental factors, and on the full harnessing and channelling of these towards creating a seamlessly fused business environment (with fluid operational modi that are relatively stable) 
In a research published by [2] on "the Six Forces of Influence on the Business Environment", it was reemphasized that "It is important for companies [businesses] to determine when and how a technology is changing an industry, and to understand the strategic influence of the new technology [on the industry]." The necessity of this importance, therefore mandates the urgency and timeliness of this paper.

\subsection{Before Computers Came}

Before the era of Computing and Information Technology, business interactions and service delivery involved compulsory physical contact between an interested buyer and a willing seller. The mandatory nature of this physical interaction further heightened as trust and integrity issues started becoming an undeniably obvious reality. And sometimes, as is still present in our current age, these trust and integrity concerns still serve as very valid determiners of business success.

Also, tenders and means of exchange of value in business transactions (currencies, collaterals, securities, etc.) needed to be carried about physically in the pre-computing business era in order to be able to take direct advantage of business opportunities. This method also posed valid concerns of vulnerabilities relating to issues of ownership, validity, security and authenticity.

Business expansion, publicity and scalability was a herculean nightmare of a task in the pre-computing era almost near impossible. Businesses could hardly grow beyond the confines of the immediate business location, and customer / consumer base was limited to those within the sphere of direct influence of the business activities, services and operations.

\subsection{Virtualization and Cloud Computing Origins}

With the advent of computers and the internet, it became possible to carry out business transactions in their completeness and entirety, and also deliver services without any form of physical interaction between buyer and seller, sometimes across amazing distances of space and time barriers. Goods and services could now be paid for without the use of physical value tenders. Encryption, Authentication, Digital Signatures, Firewalls, etc., also made it possible for issues relating to ownership, security, validity, authenticity and integrity to be adequately catered for despite the sometimes incredible distance between buyers / clients and sellers / service providers.

Business processes and activities could now be more efficiently and effectively carried out and information / results could now be stored more easily, centrally and securely, and retrieved in a timelier, ubiquitous manner. Monitoring and administration of various business units and activities could also now be more centrally done and communication became real-time.

John McCarthy, speaking at the MIT Centennial in 1961 was quoted as saying, "If computers of the kind I have advocated become the computers of the future, then computing may someday be organized as a public utility just as the telephone system is a public utility... The computer utility could become the basis of a new and important industry." [3]

One of the key computing technologies that emerged not too long after, and that has greatly transformed business practices in recent years is the technology of cloud computing and the foundational technology of virtualization that powers it.

The early years of computing and the Internet found its first use in the hands of researchers and academicians, but this changed very fast; today we have computers playing very vital roles in Healthcare and Emergency Management, in Business and Corporate Administration, and in the workings of various Governments and Economies. As the Internet continued to expand, and with the high cost of computers at the time coupled with only sparsely intermittent computational needs, businesses, organizations, researchers and academicians found it difficult owning computers because they couldn't provide any reasonable justification for investing at high costs in a computer that would sit idle for most of the time. To assuage this difficulty, entrepreneurs came up with the idea of "renting" time, making it possible for organizations and users to either own or subscribe to computing resources at much lower costs [4].

It thus became possible for users to find access to largescale mainframe computer systems using thin clients/terminal machines which were often referred to as "static terminals". They were so named because they were used mainly for communications but had no internal processing capabilities. This technology made the use of expensive mainframe systems more efficient because it allowed multiple users to share both the physical access to the computer from multiple terminals as well as to share the processing resources (CPU time). This practice, as illustrated in figure 1, was able to curb periods of "no activity" on the mainframes and allowed for greater returns on investment for companies that practiced such around the 1950s [5].

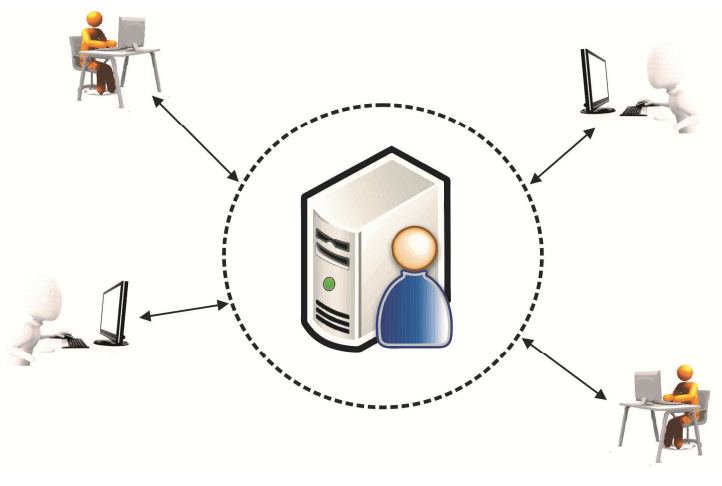

Figure 1. Cloud Computing Origins [Own Study]

This practice is what has evolved over the years to what we now call "Cloud Computing".

Cloud Computing (CC) is defined by the United States National Institute of Standards and Technology (NIST) as "a 
model for enabling ubiquitous, convenient, on-demand network_access to a shared pool of configurable computing resources (e.g., networks, servers, storage, applications, and services) that can be rapidly provisioned and released with minimal management effort or service provider interaction; having characteristics of on-demand self-service, broad network access, resource pooling, rapid elasticity and payment per usage of various business models." [6].

Virtualization is the technology that allows multiple Virtual Machines (also called guest machines) to run on a single physical machine (also called host machine) and share the resources of the physical machine [7]. This makes it possible for a single physical server to host many guest virtual machines (VMs), operating systems, and applications without the additional cost and complexity that result from running these multiple physical machines individually. [8]

The technology of Virtualization provides the abstraction that Cloud Computing enjoys by taking a physical resource such as a server (computer) and dividing it into virtual resources called virtual machines (multiple computers that can be released to subscribers) to which users (businesses) could subscribe. "This abstraction from the hardware state allows not only multiple operating systems to coexist on the same hardware, but for one VMM to run on multiple different networked physical systems concurrently. By utilizing a VMM to mediate between the OS and the hardware, virtualization changes the one-to-one mapping of OSs to hardware to many-to-many" [9] as shown in figure 2, and this forms the core of Cloud Computing as it is known today.

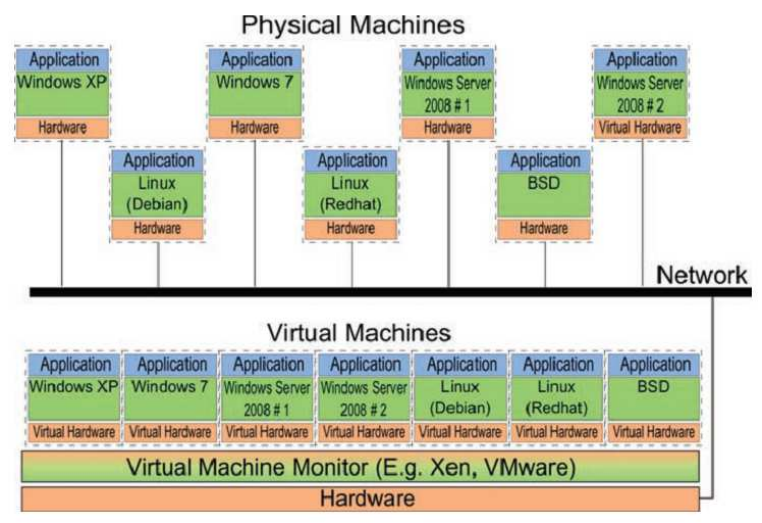

Figure 2. Many-to-Many Mapping of Operating System to Hardware [9]

Asides server and system virtualization, virtualization could also be implemented for business in the following areas as well: Storage, Networks, Desktop Infrastructures, etc.

\subsection{Cloud Computing Today}

Unlike some 30 years ago, two additional factors have significantly distinguished the technology of Cloud Computing from its predecessors and greatly altered its market dynamics. They are:

The speed, dynamism and "far-reach" of the Internet, which makes it possible to transport and deliver computational resources at high speeds, across long distances, and at reduced cost;

The ubiquity of personal computers coupled with the tendency to own computers that satisfy "peak" against "average" need for computational power, directly leaving a good reserve of computational resources idle [4]. These two factors interact as shown in figure 3 .

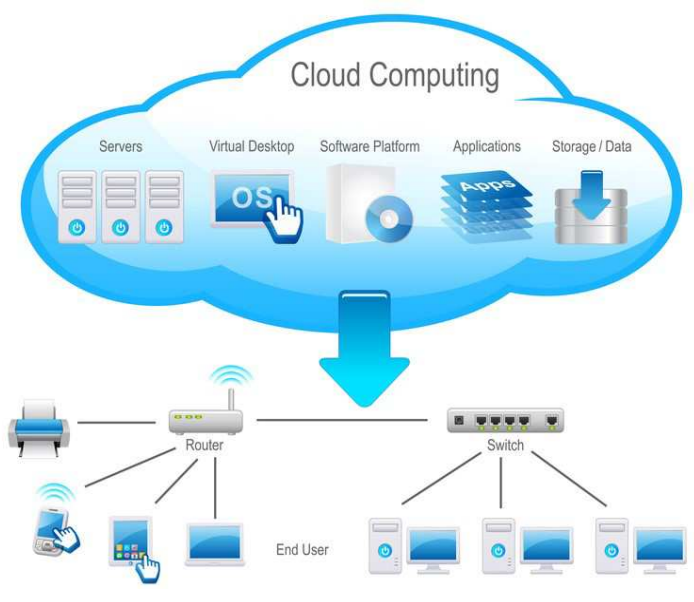

Figure 3. Cloud Computing [10]

The United States National Institute of Standards and Technology (NIST), in providing standards, guidelines, minimum requirements and specifications for Cloud Computing - [6], specify three service models for deployment in cloud infrastructure.

The first model is the Software as a Service (SaaS). In this model, clients/consumers are provided access to the applications of a provider which are deployed on a cloud infrastructure. These applications are to be made accessible to various client devices either through a thin client interface, such as a web browser (e.g., web-based email), or a through a program interface. Consumers do not manage or control the underlying cloud infrastructure including network, servers, operating systems, storage, or even individual application capabilities, with the possible exception of limited userspecific application configuration settings.

The second model is the Platform as a Service (PaaS). In this model, clients/consumers are allowed to deploy onto cloud infrastructure, consumer-created or acquired applications that are created using programming languages, libraries, services and tools supported by a provider. Consumers do not manage or control the underlying cloud infrastructure including network, servers, operating systems, or storage, but reserve control over deployed applications and possibly the configuration settings for the application-hosting environment.

Infrastructure as a Service (IaaS) is the third model. In this model, consumers are provided with processing, storage, networks, and other fundamental computing resources, using which the consumer is able to deploy and run arbitrary system and/or application software. Consumers do not control the underlying cloud infrastructure (basically hardware), but reserve control over operating systems, 
storage, and deployed application; with possibly limited control of some networking components (such as host firewalls).

The service models specified above directly define the three layers comprised in the core of most modern cloud computing infrastructure. Each of these layers offer the specified types of services to a particular segment of the consumer market while at the same time paying for the services provided by the preceding layer (except the IaaS layer) [11]. This is shown in figure 4.

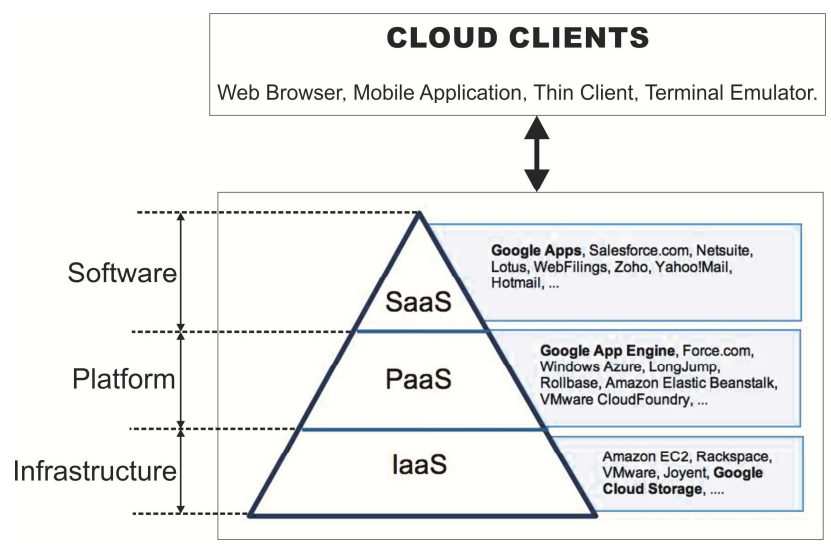

Figure 4. Cloud Computing Layers [12]

The first / foundational layer of Cloud Computing is the IaaS layer. The products here relate to hardware and associated services such as: general processing, servers, storage devices, database management, and all other hardware related services that are offered as a service to the end user. The next layer is the PaaS layer upon which developers can build and test applications that run on the IaaS, either for the IaaS layer itself or for the SaaS layer above it. The topmost layer is the SaaS, and this deals exclusively with applications for end users [11].

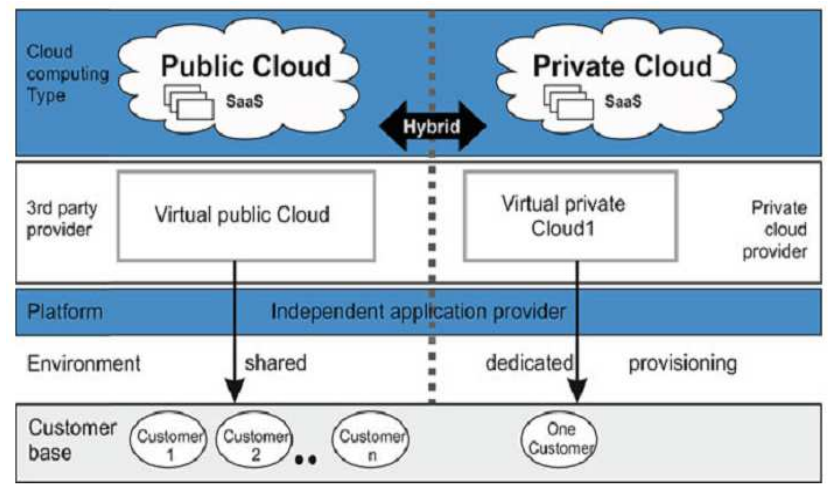

Figure 5. IaaS Deployment Variants [11]

The IaaS (the core/foundational model) variant of the CC service models could be deployed as Private Clouds (cloud infrastructure provisioned for exclusive use by a single organization comprising multiple consumers), Community Clouds (cloud infrastructure provisioned for exclusive use by a specific community of consumers from organizations that have shared concerns such as: mission, security requirements, policies, and compliance considerations), Public Clouds (cloud infrastructure provisioned for open use by the general public) or Hybrid Clouds (cloud infrastructure comprising two or more distinct cloud infrastructures, whether private, community, or public, that remain unique entities, but are bound together by standardized or proprietary technology enabling data and application portability such as cloud bursting for load balancing between clouds). The interactions between these various modes of deployment are illustrated in figure 5.

Today, Cloud computing is gradually coming to bear in reality as the most formidable path to business and organizational growth and has gained rapid interest and prominence over the past decade. The reason for this rapid growth cannot be far-fetched. Cloud computing simply makes very efficient and flexible, the task of scaling different business services to meet very dynamic business needs; the shared infrastructure and services they provide make it a more prudent venture when compared with other traditional approaches of hosting each of these infrastructure and services locally. [13]

\section{The Benefits of Virtualization for Business}

Despite the relatively cheap cost of commodity hardware and availability of networks, virtualization still has benefits that put it in the fore for most organizations. Physical systems are associated with other costs which could be operational, physical and/or technical, all in addition to the initial purchasing cost. Asides that, every physical machine bothers on physical space, cabling, energy, cooling, and software administration requirements [9]. This inadvertently makes virtualization a preferred alternative by means of system and server consolidation.

Virtualization makes it possible to test new computer and IT aided business solutions in an environment that is less vulnerable to external vices. Using methods of Sandboxing and Container Operating Systems, new, untrusted and potentially vulnerable IT business solutions can actually be tested in a more secure environment where failures and breaches of the new systems or solutions would not hamper the current smooth running of existing deployed solutions.

Legacy business solutions that are already in use and properly functioning can easily retained and run alongside new solutions deployed on virtualized platforms until these new solutions have been confirmed and smooth migration / transition has been done.

The simulation of networks and independent business units in order to study and observe the cooperation and interactions between them is made easier by virtualization. Independent business units can be simulated to run various independent processes that may either be interrelated or not, and the interactions between these can be observed more critically within a closed environment.

Virtualization further makes the previously dreaded tasks 
of migration / transition, backup and recovery of business systems a "walk-in-the-park", and the administration and management of these tasks can be more centrally done [14].

Operating Systems add a single point of failure for everything (data, processes and information) that runs on them because once an Operating System fails, everything on it is wasted with exceptions to those that have been securely backed up. The difficulty in securing this single, complicated point of failure poses a security risk for the system's data and processes and accounts for the choice of virtualization. [9]

Furthermore, modern commodity operating systems (e.g. Windows and Linux) are very complex, usually comprising of tens of millions of Lines of Code (LOC) in the latest desktop versions. This results in a much larger vulnerability surface than can be easily or provably secured [15] [16]. The fewer lines of codes in Virtual Machine Monitors thus provide a preferred alternative.

\section{The Benefits of Cloud Computing for Business}

Cloud Computing comes with immense benefits for business, some of the most popular are:

Dynamic Scalability and Flexibility - Cloud computing makes scalability and flexibility a dream come true for the business environment. Businesses can be grown and expanded and impact can be more distributed over a wider area by tapping into the resources and services provided by Cloud Computing at the Infrastructure, Platform and Software layers. As business operations and reach continues to expand, more cloud computing resources can easily be subscribed to in order to meet the growing business demands.

Reduced Management and Operational Costs - Management and Operational Costs, such as those that are incurred from power consumption, system maintenance and recruitment for IT administration, procurement of needed IT and computing devices and licencing of new important software, testing and deployment of new business solutions, amongst others, are greatly reduced by tapping into the resources of Cloud Computing (multi-tenancy, sandboxing, etc.).

Enhanced Business Agility and Ubiquity - Cloud Computing further enhances the opportunities for Agility and Ubiquity of Business operations within the business environment. Business Operations can be entirely initiated and completed without necessarily being within the physical confines of the business facility. This is possible because ubiquity is the theme behind the technology of cloud computing, and the Internet further accentuates this theme.

Simplified Storage and Management of Big Data - Before the advent of Cloud Computing, the task of managing (generating, storing and timely retrieving) Big Data, especially those generated from business operations research and market surveys was a very difficult task. It remained a nightmare to data and archives administrators until cloud computing emerged. Most modern cloud computing infrastructures provide services that make it possible to store massive amounts of data - through storage on demand provisions - in a well sorted and indexed form, thus making retrieval only as stressful as a mouse-click [17].

Smoother Transition of Business Solutions - Business Administrators can now enjoy seamless transitions from one business solution to another by simply integrating whatever new business solutions that is currently being used into their already existing cloud computing platforms or infrastructure.

Easier Mergers and Acquisitions - One of the nightmares behind mergers and acquisitions facing executives is the task of consolidating records and data from two previously distinct business endeavours. In reality, this is never really completely achieved, even for government agencies. But with cloud computing, consolidation is nothing more than a mouse-click away and end-users can readily have seamless ubiquitous access to records and data.

Superior Safety - Even though valid concerns exist relating to the reluctance of Chief Information Officers of many large corporations in opting for cloud solutions for their corporations data owing to reasons of security, privacy and policy restrictions, cloud computing security is not any less secure than the internal security of any enterprise. Cloud Providers can also implement other policy restrictions that are binding on certain clients and deploy them as private cloud facilities.

Collaboration efficiency - Collaboration is easy in a cloud environment, and it gives businesses the ability to communicate and share outside of the traditional methods. While working on a particular project from different locations, cloud computing enables employees, contractors and third parties access to the same files. A cloud computing model could also be chosen that makes it easy to share your records with advisers and prospects alike (e.g. a quick and secure way to share accounting records with your accountant or financial adviser).

Flexibility of work practices - Cloud computing allows employees to be more flexible in their work practices. For example, you can have access to data from home, on holiday, or via the commute to and from work via an internet connection. If you need access to your data while you are offsite, you can connect to your virtual office, quickly and easily.

Green Benefits - Cloud Computing also offers green benefits because cloud providers can invest in data centres on an ultra-large scale (thus reducing the global energy waste contributions of individual companies), thus offering companies a green alternative to conventional approaches to IT. Also, by subscribing to more cloud services, material waste is reduced as less non-biodegradable hardware is required. In addition, less infrastructure on site means less equipment to insure [17].

\section{Industry Perspectives and Opinions}

Despite the fact that a comprehensive survey by [18] revealed that ICT executives [and business managers] believe that the greatest influence that ICT will have on their enterprise's ability to remain competitive in the future will be 
by increasing performance $(72 \%)$ and achieving cost savings $(70 \%)$, as well as knowledge acquisition and management $(69 \%)$ amongst others as shown in figure 6 , recent server watch technical reviews and white-paper reports insight that virtualization is rapidly taking over the IT and business industry at such a pace that tends to suggest that it is becoming increasingly difficult for businesses and professionals alike to keep up [19] [20]. The absence of a proper understanding of some major concepts and areas as well as the immense benefits of Virtualization has, no doubt, added to the scepticisms of businesses in opting for full virtualization of their IT Infrastructure; thus necessitating the need for this exposé.

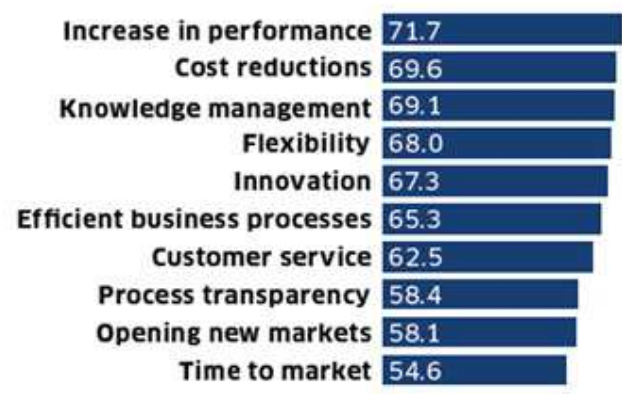

Figure 6. ICT and competitive ability [18]

\section{The Future of Virtualization and Cloud Computing}

The most important prospect for Cloud Computing lies in the possibility for government and economic fiscal policies to begin to rise in its favour (particularly for financial institutions), especially in developing and underdeveloped countries as it has in most developed countries of our world. This is suggested by the fact that government agencies have begun to partake in the eating of the Cloud "pudding" and are gradually becoming more convinced about its "taste" with every passing stride.

The ubiquity of Cloud Computing has a more promising future as more mobile implementations of cloud services are beginning to emerge. In the coming years, more already cloud services, as well as those yet to come would feature fully functional mobile implementations, making them more flexible and easy to use; with this prospect would also come the capability for better remote monitoring, access and delivery because cloud services provided and delivered in this line would thrive on this.

The Cloud of the future hopes to feature a more centralized database for storage, access and retrieval of data on-demand. This would prove very valuable in areas such as healthcare and medical records management. More organizations would be able to generate new, and equally have access to existing databases of massive records. This would make more effective the job of prospecting and monitoring of trends.

Businesses and Organizations are beginning to get more interested in investing in applications that promote business as against those that promote IT. This was revealed in a 2013 survey published by North Bridge Venture Partners [21]. The survey revealed that an average $52 \%$ of organizations currently use of applications that advance business priorities, as against an average $36 \%$ of organizations that use applications that advance IT priorities; thus further underscoring the increasing value placed by organizations on facilitating the delivery of services beyond IT via the cloud.

Also, the Consumer-base of Private and Public Clouds are expected to grow in the coming years as the use of public [as well as private] cloud applications continue and increase across the IaaS, Saas and PaaS layers. Private cloud will likely continue to be the preferred approach where it is feasible, but at the enterprise application layer (applications relating to Customer Relationship Management, Human Capital Resource Management and IT Service Management) public cloud SaaS applications would be more likely to reign [22].

Security concerns are gradually also beginning to lose their reputation as the primary inhibiting factor for cloud computing. Even though it still tops the list of inhibitors, the same survey by [21] also stated that an average $46 \%$ of respondent organizations pointed out security concerns as the primary inhibitor for cloud computing in 2013, down from an average $55 \%$ in 2012 . This suggests that more organizations and businesses would be more reception to cloud computing technologies in the coming years.

More standards are also coming into place to ensure enhanced portability of data across various cloud platforms. This has eased up integration and interoperability concerns to a large extent, and prospects for the coming years are also promising [21].

\section{Conclusion}

The business environment of the $21^{\text {st }}$ Century is becoming increasing dynamic. New trends and technologies are rapidly emerging and transforming businesses for the best. The corporations that lead and constantly top the charts in this dynamic business environment have been known to be those that are able to early enough discover, understand, and effectively harness these new emerging technologies for their benefits, and their profits have always increased well beyond exponential margins and indices.

Past researches in business and IT have proven that Virtualization and Cloud Computing may hold the key to business performance enhancement, sustainability and productivity, and this paper has thrown in a couple more reasons to uphold this fact, posing in solidarity with past similar researches, and further opening some new insights into what the future holds for these twin technologies.

This paper has been able to integrate the concepts behind the internal workings of virtualization and cloud computing and prove their relevance as formidable technologies for business success in this century, and further highlighting their unique benefits to businesses in the most compact form possible that still retains relevance.

IT and business managers, executives, decision makers and 
policy implementers would find this exposé to be one very compact, interesting read and an indispensable reference material, comparable to very few others, that they can readily fall back on to support their decisions for choosing virtualizations and cloud computing as the preferred technologies for positioning their businesses for the coming digital revolution. However, while this paper presents one of the most compact exposés and overviews on virtualization and cloud computing and prospects for businesses, which could provide handy key points for managers and executives in IT and business, we recommend [23] for a more detailed and in-depth perspective on these twin technologies.

Despite the promising benefits and future prospects above, it is noteworthy to emphasize that the cloud of the future would really be nothing like we have ever imagined. Cloud computing is expected to rise way over and beyond its current seemingly imposing limitations with renewed and determined force; and those businesses that would embrace the cloud today would be those that would become well aligned with their consumer requirements, and properlypositioned for continued success.

\section{References}

[1] The Business Dictionary. (2014). What Is Business Environment? Definition and Meaning. Retrieved from BusinessDictionary.com:

http://www.businessdictionary.com/definition/businessenvironment.html

[2] Sievers, R. L. (2008). The Business Environment - Six Forces of Influence. Sievers \& Co.

[3] Arora, R., \& Bajaj, K. S. (2013, March). Highly Effective Advanced Technology "HEAT" Re-defining Technology for Hospital Management. International Journal of Management \& Behavioural Sciences, Special Edition, 68-73.

[4] Davies, A. (2004, June). Computational intermediation and the evolution of computation as a commodity. Applied Economics, 36(11: 1131). doi:10.1080/0003684042000247334

[5] Christopher, S. (1959). Time Sharing in Large Fast Computers Proceedings of the International Conference on Information processing, UNESCO. 2.19, pp. 336-341. UNESCO. Retrieved February 1, 2014

[6] Mell, P., \& Grance, T. (September 2011). The NIST Definition of Cloud Computing. Computer Security Division, Information Technology Laboratory, National Institute of Standards and Technology, United States Department of Commerce. Gaithersburg, MD 20899-8930: National Institute of Standards and Technology. Retrieved January 28, 2014, from http://csrc.nist.gov/publications/nistpubs/800145/SP800-145.pdf

[7] Ryan, S., \& Jiangchuan, L. (2012). Understanding the Impact of Denial of Service Attacks on Virtual Machines. Journal of the IEEE.

[8] Tupakula, U., \& Varadharajan, V. (2011). TVDSEC: Trusted Virtual Domain Security. Institute of Electrical and Electronic Engineers (IEEE), 57-63.
[9] Pearce, M., Zeadally, S., \& Hunt, R. (2013, February). Virtualization: Issues, Security Threats, and Solutions. Association for Computing Machinery (ACM) Computing Surveys, Article 17: 1-39.

[10] Cloud Computing in India. (2013). Cloud Computing in India. Retrieved May 26, 2014, from Best Cloud Computing Companies, Cloud Computing Companies in India, Cloud Computing in India: http://www.cloudcomputinginindia.in/

[11] Strømmen-Bakhtiar, A., \& Razavi, A. R. (2011). Cloud Computing Business Models. Springer Computer Communications and Networks, 43-60.

[12] Gartner AADI Summit. (2009). Cloud Computing as Gartner Sees it. Gartner's Application Architecture, Development \& Integration Summit.

[13] Nagaraju, K., \& Sridaran, R. (2012, September). A Survey on Security Threats for Cloud Computing. International Journal of Engineering Research \& Technology (IJERT), Volume 1 (Issue 7), 1-10.

[14] Texas Reliability Entity. (2013). Virtualization and Cloud Computing. "Security is a Process, not a Product". Texas, USA.: Texas Reliability Entity.

[15] Franklin, J., Seshadri, A., Qu, N., Chaki, S., \& Datta, A. (2008). Attacking, Repairing, and Verifying SecVisor: A Retrospective on the Security of a Hypervisor. Cylab Technical Report. CMU-Cylab-08-008.

[16] Seshadri, A., Luk, M., Qu, N., \& Perrig, A. (2007). SecVisor: A Tiny Hypervisor to provide lifetime Kernel code integrity for commodity OSes. Proceedings of the 21st ACM SIGOPS Symposium on Operating Systems Principles (pp. 335-350). Association for Computing Machinery.

[17] Ross, A. (October 2013). How Cloud Computing Benefits Your Company. Smart Data Collective. Retrieved May 28, 2014, from http://smartdatacollective.com/asher-ross/150686/10ways-know-how-cloud-computing-benefits-your-company

[18] Kretschmer, T. (2010). "WORK - Working Connected in Business and Society”. Bonn, Germany.: Deutsche Telekom AG.

[19] Oltsik, J., \& Laliberte, B. (April, 2012). HP Virtual Application Networks. Enterprise Strategy Group (ESG), Inc. Milford, MA 01757, Massachusetts, USA.: Enterprise Strategy Group (ESG), Inc. in collaboration with Hewlett Packard (HP).

[20] Rubens, P. (2013, September 30). Addressing the Virtualization Disconnect. Retrieved from ServerWatch Everything Servers: Virtualization, Blades, Power \& Cooling Technology News, Trends and Analysis for Server Admins: http://www.serverwatch.com/server-trends/addressing-thevirtualization-disconnect.html

[21] Jones, E. (2013). 2013 Future of Cloud Computing Survey Reveals Business Driving Cloud Adoption in Everything as a Service Era; IT Investing Heavily to Catch up and Support Consumers Graduating from Bring Your Own Device (BYOD) to Bring Your Own Cloud (BYOC). Palo Alto, California.: North Bridge Venture Partners. Retrieved May 28, 2014, from http://www.northbridge.com/2013-future-cloud-computingsurvey-reveals-business-driving-cloud-adoption-everythingservice-era-it 
177 Emmanuel Chinomso Ogu et al:: Virtualization and Cloud Computing: The Pathway to Business Performance Enhancement, Sustainability and Productivity

[22] Morrissey, M. (2014, January 10). The Future of Cloud Computing - Perspecsys. Retrieved from Cloud Data Security, Secure Cloud Data Encryption | Perspecsys: http://perspecsys.com/future-cloud-computing/
[23] Williams, B. (2012). The Economics of Cloud Computing.An Overview for Decision Makers. Cisco Press, Indianapolis, Indiana, USA. 